\title{
Aspectos de la transformación de las cooperativas de crédito tras la Ley de Modificaciones Estructurales de 2009*
}

\author{
Isabel-Gemma Fajardo García \\ Prof. Titular Derecho Mercantil \\ Universitat de València
}

Sumario: I. Introducción. II. La transformación. Reconocimiento y ámbito. III. La transformación de cooperativas. Regulación y problemática jurídica. a) La regulación de la transformación de cooperativas. Evolución. b) Problemática jurídica que plantea la transformación de cooperativas. IV. Régimen jurídico aplicable a la transformación de cooperativas. V. La transformación de cooperativas de crédito y el destino de sus reservas irrepartibles.

Resumen: La Ley 3/2009 sobre modificaciones estructurales de las sociedades mercantiles ha modificado la ley de cooperativas de crédito con el fin de regular ciertos aspectos de la transformación de estas entidades, y en particular el destino que debe darse a su Fondo de reserva obligatorio en esos procesos, que deberá integrarse en el capital social de la nueva entidad.

El presente trabajo analiza la transformación como modificación estructural a disposición de las cooperativas y en particular de las cooperativas de crédito; su reconocimiento en la ley y en la jurisprudencia española, a lo largo del tiempo; la problemática jurídica que plantea y en particular, el destino de su Fondo de reserva obligatorio; y concluye con una propuesta interpretativa del actual art. 10.2 de la Ley de cooperativas de crédito, que compatibiliza los intereses subyacente en la reforma, con los valores y principios cooperativos.

Palabras clave: cooperativas de crédito, transformación, fondo de reserva obligatorio, capital social.

Abstract: Law 3/2009 on structural changes in corporations modified the law on cooperative credit unions in order to regulate certain aspects of con-

* Este trabajo forma parte del proyecto de investigación financiado por el Ministerio de Ciencia e Innovación que lleva por título La Economía Social en las políticas públicas. Perspectiva de política económica (DER2009-14462-C02-02) y tuvo como origen contribuir al Libro Homenaje al Profesor Vicente Cuñat Edo: Estudios de Derecho del Mercado Financiero, publicado por la Universidad de Valencia. 
verting these, with special focus on how mandatory reserve funds should be used in these processes and which must be included in the new entity's share capital.

This work analyses conversion as a structural modification available to cooperatives, particularly credit cooperatives; their acknowledgment by law and in Spanish jurisprudence over time; the legal problems posed, and particularly the use of mandatory reserve funds. The study concludes with a proposal for interpretation of the current article 10.2 of the Law on credit cooperatives, which makes the underlying interests of the reform compatible with cooperative values and principles.

Keywords: credit cooperatives, transformation, mandatory reserve funds, share capital. 


\section{Introducción}

La Ley 3/2009, de 3 de abril, sobre modificaciones estructurales de las sociedades mercantiles (LME), ha introducido en su DF $4 .^{\circ}$ una modificación a la Ley de cooperativas de crédito 13/1989 (LCC), en particular a su art. 10.

Este artículo regulaba brevemente la fusión y escisión de cooperativas de crédito. En concreto contenía dos normas. Según la primera, las fusiones, escisiones o absorciones que afecten a una cooperativa de crédito requerirán autorización administrativa previa; y según la segunda, en el caso de que la entidad resultante de la fusión, escisión o absorción fuera una cooperativa de crédito, ésta deberá solicitar su inscripción en el Registro correspondiente del Banco de España.

La LME ha introducido en dicho precepto diversas modificaciones: principalmente, por una parte, extiende a los supuestos de transformación la necesidad de autorización administrativa previa y el deber de solicitar la inscripción en el Registro del Banco de España; y por otra, establece una regulación específica para el caso de transformación, que es objeto de nuestra atención.

Según el nuevo art. 10.2, cuando una cooperativa de crédito se transforme en otra entidad de crédito, el Fondo de Reserva Obligatorio de aquella pasará a integrarse en el capital social de la entidad resultante de la transformación ${ }^{1}$. La medida es novedosa y de una importancia vital para las cooperativas de crédito. Pero para poder valorar debidamente su alcance debemos referirnos previamente al sentido de esta modificación estructural y a su aplicación a las cooperativas.

\section{La transformación. Reconocimiento y ámbito}

La transformación es un tipo de modificación estructural por la que una entidad con personalidad jurídica, cambia su tipología y estatuto jurídico, conservando su personalidad y sin que se produzca sucesión en las relaciones jurídicas establecidas. La decisión de transformarse es adoptada por la persona jurídica conforme a un procedimiento previsto legalmente, que tiene como objetivo ofrecer seguridad jurídica a los sujetos que pueden verse afectados por dicho proceso: socios y acreedores, principalmente. Las razones por las que una entidad decide trans-

1 La norma se complementa con una referencia a las consecuencias fiscales de dicha transformación. 
formarse pueden ser diversas, desde la necesidad a la oportunidad²; en cualquier caso, el objetivo es adaptar la estructura jurídica para permitir dar continuidad a la empresa.

La transformación no estaba prevista inicialmente en nuestra legislación entre las posibles modificaciones estructurales de las sociedades; la entidad que quisiera modificar su tipo debía proceder a su disolución y liquidación para posteriormente fundar el tipo social elegido, lo que resultaba largo, costoso y perjudicial para el crédito de la empresa.

Es con la LSA 1951 cuando por vez primera se regula en nuestro ordenamiento la transformación de sociedades; en particular, la transformación de sociedades anónimas en sociedades colectivas, comanditarias o de responsabilidad limitada (art. 133), y viceversa (art. 140). Se trata de la transformación entre las distintas formas de sociedad mercantil previstas en nuestro ordenamiento (arts. 122 C. de c. y leyes especiales). Fuera de estos supuestos, no se ve posible llevar a cabo este tipo de modificaciones, y el art. 133 LSA declaraba nula cualquier transformación en un tipo de sociedad distinto. Este régimen se mantiene en el TRLSA de 1989 (arts. 223 a 231), y se amplía subjetivamente con la Ley 12/1991 de Agrupaciones de interés económico (art. 19).

Como afirmaba Girón, con la transformación se conserva la individualización e identificación subjetivas pero pueden modificarse muchos aspectos patrimoniales, por lo que la posibilidad de transformación es una cuestión esencialmente «jurídico-positiva, porque sin disposiciones que concretamente lo establezcan no puede imponerse a los acreedores un cambio en el sujeto pasivo de las relaciones jurídicas», y pone como ejemplo las diferencias de régimen existentes entre una sociedad colectiva y una sociedad anónima. No obstante, como también reconoce este autor, la tendencia, sobre todo en derecho comparado, ha sido la de ir permitiendo la adaptabilidad de las estructuras empresariales, haciéndola compatible con las garantías debidas a terceros y con el respeto de la relación de cada tipo con el sector económico-social al que corresponde ${ }^{3}$.

Siguiendo esta tendencia, la Ley 2/1995 de Sociedades de Responsabilidad Limitada (LSRL) amplió notablemente el perímetro sub-

2 Las razones que pueden llevar a una entidad a decidir su transformación pueden ser innumerables, desde facilitar la obtención de capital, reducir costes, mejorar el control de la sociedad, obtener ventajas fiscales, articular procesos de reestructuración empresarial como la constitución de grupos, etc., o simplemente se busca una forma jurídica que se adapte mejor a los fines perseguidos por los socios.

3 Giron Tena, J.: Derecho de sociedades, tomo I, Madrid, 1976, pp. 354 y 357. 
jetivo de esta modificación estructural, reconociendo la posibilidad de transformación de la SRL en sociedad colectiva, comanditaria, anónima y en agrupación de interés económico; así como en sociedad civil si su objeto social no es mercantil, y en sociedad cooperativa, de conformidad con lo previsto en la legislación reguladora de ésta (art. 87). También se contemplaba expresamente la posibilidad de transformación de la SRL en todos los tipos anteriormente citados (arts. 92 y 93), y se establecían ciertas garantías que debían respetarse en ese proceso.

Por último, la LME aprobada el 3 de abril de 2009 se presenta como una concreción más del proceso de perfeccionamiento del derecho de sociedades mercantiles, tendente a la consecución de diversas finalidades; entre ellas, unificar y ampliar el régimen jurídico de las denominadas «modificaciones estructurales». Así, con la unificación se pretende crear un único régimen aplicable, derogando los anteriormente previstos en la LSRL y LSA; mientras que la ampliación supone incorporar al elenco clásico de modificaciones estructurales (transformación, fusión y escisión) la cesión de activos y pasivos; aunque también podría considerarse un supuesto de ampliación, la extensión del perímetro subjetivo de las transformaciones posibles.

La LME comienza declarando que su objeto es regular las modificaciones estructurales de las sociedades mercantiles (art. 1)4, aclarando a continuación que por tanto es aplicable a todas las sociedades que tengan la consideración de mercantiles, bien por la naturaleza de su objeto (sociedades colectivas y comanditarias), bien por la forma de su constitución (anónimas, limitadas, agrupaciones de interés económico y sociedades de garantía recíproca). Sin embargo, como adelanta su exposición de motivos, en materia de transforma-

${ }^{4}$ El legislador español ha optado por tratar conjuntamente las modificaciones estructurales de las sociedades mercantiles y no ampliar su tratamiento a las personas jurídicas de derecho privado como se ha hecho en Alemania. En Italia, el Código civil, tras la reforma operada por el D. Legs 17 enero 2003 núm 6, también ha ampliado su ámbito más allá de las sociedades y regula, la transformación de sociedades de personas en sociedades de capital y viceversa (art. 2500-ter y 2500-sexies), y transformaciones heterogéneas de sociedades de capital (por acciones, comanditarias por acciones y responsabilidad limitada) en consorcios, sociedades consorciales, cooperativas, comunidades de empresas, asociaciones no reconocidas (sin personalidad jurídica) y fundaciones (art. 2500-septies); y las transformaciones recíprocas de consorcios, sociedades consorciales, comunidades de empresas, asociaciones reconocidas y fundaciones, en sociedades de capital (art. 2500-octies). 
ción la ley amplía su perímetro de aplicación a las sociedades civiles y cooperativas (art. 4).

\section{La transformación de cooperativas. Regulación y problemática jurídica}

Como hemos visto, la transformación es un mecanismo jurídico que permite modificar el tipo societario manteniendo la titularidad subjetiva de las relaciones jurídicas establecidas hasta el momento por la entidad transformada. El mantenimiento de la personalidad jurídica de la entidad transformada no impide que ésta sufra importantes modificaciones como consecuencia de dicho proceso.

Estas alteraciones pueden afectar a su patrimonio, a su responsabilidad, o a su objeto social; por ello, tanto la doctrina como la jurisprudencia, han venido defendiendo en garantía de los terceros, la imposibilidad de proceder a la transformación de una entidad si una ley no lo prevé y adopta las garantías oportunas. A ello se debe que la implicación de la cooperativa en un proceso de transformación no ha sido posible hasta que el legislador lo ha regulado.

\section{a) La regulación de la transformación de cooperativas. Evolución}

La regulación de la transformación de la cooperativa llega en los años 90. Con anterioridad encontramos algunos supuestos concretos de transformación en la Ley 33/1984 de ordenación del seguro privado, en la legislación cooperativa autonómica y en la Ley general de cooperativas de 1987.

La Ley 33/1984 tenía entre sus objetivos —según su exposición de motivos - fomentar la concentración de empresas y consiguientemente la reestructuración del sector de los seguros en el sentido de dar paso a grupos y empresas más competitivas nacional e internacionalmente y con menores costes de gestión. Por ello reconocía ampliamente los procesos de fusión, transformación, escisión y agrupación de las empresas aseguradoras.

En particular según su art. 28.3, las entidades de seguros podrían transformarse en sociedades de otra naturaleza jurídica o clase, autorizadas por la ley. Las formas jurídicas autorizadas eran, la sociedad anónima, sociedad mutua a prima fija, sociedad mutua a prima variable, montepío o mutualidad de previsión social y la sociedad cooperativa (art. 7). El problema que plantea esta norma es que permite la transformación pero no regula su procedimiento ni las garantías oportunas, 
ni tampoco lo hace la legislación cooperativa aplicable supletoriamente (Ley Cooperativas 52/1974) $)^{5}$.

Poco después, la ley valenciana de cooperativas 11/1985 reconocía y regulaba la transformación de mutuas de seguros y mutualidades de previsión social en cooperativas de seguros; y de economatos de empresas en cooperativas de consumidores y usuarios (DF 4. ${ }^{\text {a)}) ; ~ y ~ l a ~ l e y ~ a n-~}$ daluza de cooperativas 2/1985, la transformación en cooperativas de las sociedades agrarias de transformación (DT 3. ${ }^{\circ} 3$ ).

La LGC 3/1987 reconoció y reguló en su DA 3. ${ }^{a}$ la transformación de sociedades agrarias de transformación en sociedades cooperativas agrarias, cooperativas de explotación comunitaria de la tierra o de trabajo asociado; y la transformación en este último tipo de cooperativa de las sociedades anónimas laborales, y demás sociedades anónimas y limitadas, en las que los trabajadores de las mismas sean titulares, al menos, del $50 \%$ del capital social, y ningún socio ostente más del 25 por 100 del referido capital6.

Pero como decimos, la posibilidad de transformación de las cooperativas en otras formas sociales y viceversa, de una forma general, tiene lugar a lo largo de los años $90^{7}$.

5 La Ley 33/1984 se limita a establecer al respecto, el derecho de los asegurados a resolver, por esta causa, los contratos de seguro (art. 7 y art. 84.7 Reglamento 1985). Por otra parte, su Reglamento, aprobado por RD 1348/1985 exigía para la transformación, la autorización del Ministerio de Economía y Hacienda, para lo que deberían aportar la documentación y cumplir los requisitos que éste estableciera; y la difusión del proyecto mediante información pública en la que los asegurados pudieran expresar, en su caso, las razones de su disconformidad. Por último, se establece la formalización de la transformación en escritura pública y su inscripción en los registros correspondientes; y la autorización para que la entidad resultante de la transformación, pueda superar el margen de solvencia establecido en el Reglamento (art. 84.6).

6 La citada disposición recoge una amplia regulación del procedimiento de transformación y de sus consecuencias. Esta norma contempla exclusivamente la cooperativa como resultado de la transformación, pero en cambio regula el procedimiento a seguir por la sociedad a transformar, que como hemos visto podría ser una sociedad civil, mercantil, laboral o una sociedad agraria de transformación. Especial interés tiene la mención a la posibilidad de transformación de sociedades civiles o mercantiles en cooperativas de trabajo asociado, si sus trabajadores son titulares de al menos el $50 \%$ del capital social, y ningún socio ostenta más del $25 \%$ del referido capital. Norma que nos recuerda la recién aprobada ley de sociedades anónimas laborales de 25 de abril de 1986, en un contexto de crisis del sector industrial, que llevó a la reconversión de muchas empresas y al cambio de su forma jurídica para poder ser continuadas y saneadas por sus trabajadores asumiendo la condición de socios.

7 Durante estos años, tiene lugar en nuestro ordenamiento el reconocimiento generalizado de las transformaciones heterogéneas; consecuencia en parte de las recomendaciones procedentes de la Unión Europea. En este sentido, Vicent Chulia, F.: «Reforma del régimen de la fusión y otras modificaciones estructurales (Ante la Directiva 2005/56/ 
La primera norma destacable fue la Ley 4/1993, de Cooperativas del País Vasco, que regula en sus arts. 85 y 86 la transformación de cooperativas en sociedades civiles o mercantiles de cualquier clase; y la transformación de sociedades y agrupaciones en cooperativas, siempre que no exista un precepto legal que lo prohíba expresamente. Según su exposición de motivos, con estas normas se pretende cubrir las numerosas lagunas que tiene la regulación de esta materia en el ordenamiento vigente; y para ello, se han tenido en cuenta dos principios: evitar que la transformación de cooperativas llegue a diluir o incluso desnaturalizar la esencia cooperativa ${ }^{8}$, y aprovechar las técnicas normativas del moderno derecho de sociedades. En términos muy similares se pronunció poco después la Ley valenciana 3/1995, de 2 de marzo, de modificación de la ley de cooperativas $11 / 1985$, en sus arts. 68 y $69^{9}$.

En el mismo año, la LSRL 2/1995 a la que hicimos anteriormente referencia, reconoce expresamente la transformación de la sociedad de responsabilidad limitada en sociedad cooperativa, de conformidad con lo previsto en la legislación reguladora de esta última10; y la transfor-

CE sobre fusión transfronteriza y el 14 de junio de 2007)» RDP núm 20, pp. 25-76, hace referencia a diversas normas de la Comisión Europea que aconsejan a los Estados miembros facilitar la transformación heterogénea hacia formas societarias más idóneas para la sucesión (Comunicación de 29 de junio de 1994 sobre «La transmisión de empresas: acciones a favor de las pequeñas y medianas empresas» y Recomendación 94/1069/CE de 7 de diciembre de 1994, DOCE L 385/14, de 31 de diciembre).

8 Por ello posiblemente, se condiciona la transformación a la existencia de necesidades empresariales que exijan soluciones inviables en el sistema jurídico cooperativo, a juicio de los administradores y, en su caso, de la comisión de vigilancia de la cooperativa, homologado por el Consejo Superior de Cooperativas de Euskadi; y se asegura el destino de las dotaciones del Fondo de Reserva Obligatorio y de las reservas voluntarias irrepartibles, que se acreditarán al Consejo Superior de Cooperativas de Euskadi (CSCE), como título de cuentas en participación en la sociedad resultante del proceso transformador; y el destino del Fondo de Educación y Promoción Cooperativa, que se aplicará conforme prevean los estatutos y en su defecto, es pondrá a disposición del CSCE.

9 Esta ley también recoge la exigencia de justificar que la transformación se hace por necesidades empresariales que no pueden atenderse razonablemente en régimen cooperativo, y asegura el destino de los fondos irrepartibles de la cooperativa. El fondo de reserva obligatorio podrá acreditarse a favor de los destinatarios estatutarios o legales de estos fondos, como cuentas en participación de la sociedad resultante de la transformación, o como créditos retribuidos a un interés de tres puntos sobre el legal del dinero, que se reembolsarán en el plazo máximo de cinco años.

10 También debe tenerse en cuenta el desarrollo de esta norma por el art. 222 RRM, del que destacamos que, para poder transformar una sociedad limitada en cooperativa, debe indicarse la legislación cooperativa que admita o permita la transformación y habrá que incorporar al procedimiento certificación del RM en el que consten las declaración de inexistencia de obstáculos para la inscripción de la transformación. Sobre cuál podría ser el contenido de esta declaración: Paz Canalejo, N.: La Sociedad Cooperativa ante el 
mación de sociedades cooperativas en sociedades de responsabilidad limitada conforme al procedimiento establecido en el art. 93 (precepto desarrollado por el art. 218 RRM). Entre otras medidas, este artículo exige para la inscripción de la transformación en el RM, la presentación de la certificación del Registro de cooperativas correspondiente, en la que consten entre otras menciones, la declaración de inexistencia de obstáculos para la inscripción de la transformación. El precepto establece también un régimen aplicable a la transformación de cooperativas en sociedades de responsabilidad limitada para el caso de que no existan normas específicamente aplicables ${ }^{11}$. Entre estas normas podemos destacar la que determina que el Fondo de Reserva Obligatorio, el Fondo de Educación y Promoción y cualesquiera otros Fondos o Reservas que no sean repartibles entre los socios, recibirán el destino establecido para el caso de disolución de las sociedades cooperativas.

También en 1995 merece destacarse dos normas que afectarán a la posibilidad de transformación de dos tipos específicos de cooperativas, la Ley 30/1995, de ordenación y supervisión de los seguros privados, y el Real Decreto 1245/1995, sobre creación de bancos, actividad transfronteriza y otras cuestiones relativas al régimen jurídico de las entidades de crédito.

La Ley 30/1995 admitía la transformación de cooperativa de seguros a prima variable, en mutua y cooperativa a prima fija o en sociedad anónima, y de cooperativa de seguros a prima fija en sociedad anónima. También cabía la posibilidad de que una mutua de seguros a prima variable se transforme en cooperativa a prima fija; cualquier otro supuesto de transformación será nulo, salvo que excepcionalmente lo autorice el Ministro de Economía y Hacienda (art. 23). Según este precepto, el régimen aplicable a la transformación de entidades aseguradoras es común y se regirá por lo previsto en esta Ley ${ }^{12}$ y en la Ley de

reto de los mercados actuales. Un análisis no sólo jurídico, Ministerio de Trabajo y Asuntos Sociales, Informes y Estudios, 2002, pp. 206-207.

11 La norma podría interpretarse en un doble sentido: se establece un régimen para la transformación, en el caso de que la legislación cooperativa aplicable admita la transformación pero no la regule; o bien, ese régimen será aplicable también en el caso de que la legislación cooperativa no prevea la transformación de cooperativa en sociedad de responsabilidad limitada. Pensamos que sólo es admisible la primera interpretación, en la medida en que la competencia para regular la cooperativa corresponde a las Comunidades Autónomas, que deben ser soberanas para admitir o no estas modificaciones estructurales.

12 La LOSSP se desarrolló por el Reglamento aprobado por RD 2486/1998 cuyo art. 71 regula ampliamente la transformación de entidades aseguradoras, exigiendo entre otros requisitos, que el proyecto de transformación especifique las causas de la misma. 
sociedades anónimas. Con la aprobación del texto refundido de la ley por RD. Leg 6/2004, el contenido de esta norma se encuentra recogido en el art. 24.

Por otra parte, el RD 1245/1995, en su DA 4. ${ }^{a}$ bajo el título de Autorización para la transformación en bancos de sociedades ya constituidas, reconoce la posibilidad de transformar cooperativas de crédito en bancos siempre que reúnan los requisitos exigidos para la creación de éstos en el Titulo I de dicho Real Decreto ${ }^{13}$. La norma es criticable, por su carácter reglamentario ${ }^{14}$, por la ausencia de una norma legal que permitiese la transformación de cooperativa de crédito en sociedad anónima ${ }^{15}$, y por no articular medidas que garantice los intereses de socios y terceros en ese proceso de transformación.

Por último hay que hacer referencia a la vigente Ley estatal de cooperativas 27/1999, que a diferencia de su predecesora, recoge de forma general y amplia la transformación de cooperativas en su art. 69. Según este precepto, cualquier asociación o sociedad que no tenga carácter cooperativo y las agrupaciones de interés económico, podrán transformarse en una sociedad cooperativa siempre que, en su caso, se cumplan los requisitos de la legislación sectorial y que los respectivos miembros de aquellas puedan asumir la posición de cooperadores en relación con el objeto social previsto para la entidad resultante de la transformación. Asimismo, las sociedades cooperativas podrán transformarse en sociedades civiles o mercantiles de cualquier clase.

\section{b) Problemática jurídica que plantea la transformación de cooperativas}

La normativa analizada pone de relieve cómo partiendo de la imposibilidad de participación de la cooperativa en procesos de transformación, el legislador ha ido reconociendo cada vez más y de forma más amplia, esa posibilidad.

13 Entre dichos requisitos, el art. 2.1 b) exige para realizar la actividad bancaria tener un capital social inicial no inferior a 18.030.363 euros, desembolsado íntegramente en efectivo y representado por acciones nominativas. En caso de transformación, este requisito se entenderá cumplido siempre que la suma del patrimonio neto resultante de su balance reciente auditado y de las aportaciones en efectivo alcancen dicho importe.

14 En este sentido, la norma fue criticada por Vicent Chulia, F.: «Las modificaciones estructurales de sociedades tras la Ley de Sociedades de Responsabilidad Limitada y el Reglamento del Registro Mercantil», RJC núm 3, 1997, p. 62.

15 La legislación sobre sociedades anónimas (RD Leg. 1564/1989) no contemplaba este supuesto en su art. 231, ni tampoco la legislación cooperativa vigente en el momento (LGC 1987 y Ley 13/1989 de Cooperativas de Crédito). 
Las razones que dificultaban ese reconocimiento son fácilmente entendibles, y todavía son tenidas en cuenta en otros países donde sigue sin ser posible la transformación entre entidades de naturaleza jurídica diferente, como la cooperativa y las sociedades mercantiles ${ }^{16}$.

Las sociedades mercantiles comparten la misma naturaleza lucrativa, sin embargo, hasta 1951 no se reconoció la posibilidad de transformarse entre sí, y ello fue posible porque el legislador estableció garantías para asegurar los intereses de socios y terceros ${ }^{17}$, siendo el principal escollo la diversa responsabilidad de los socios, y consecuentes garantías de los acreedores, en las sociedades personalistas y capitalistas.

Si analizamos las diferencias existentes entre entidades de distinta naturaleza se comprende que las garantías establecidas para la transformación de las sociedades mercantiles no sean suficientes. Así podríamos plantearnos si es posible y bajo qué condiciones, la transformación de una sociedad anónima en cooperativa, en asociación, en fundación; o la transformación de una fundación, asociación o cooperativa en una sociedad mercantil. Limitando nuestro análisis a la cooperativa y a las sociedades mercantiles, podríamos distinguir las siguientes peculiaridades que deben tenerse en cuenta ante un proceso de transformación:

a) Para que pueda transformarse una sociedad mercantil en una cooperativa, es necesario que los socios además de aportar capital social pasen a ser socios cooperadores, esto es, partícipes en la actividad de la cooperativa, bien como proveedores, usuarios o consumidores, o bien como trabajadores. No se trata de asumir prestaciones accesorias. Esta relación económica que va

16 En Portugal, el art. 80 del Código Cooperativo aprobado por Ley núm. 51/1996 declara la nulidad de la transformación de la cooperativa en cualquier tipo de sociedad comercial, y en Italia, el Código civil, tras la reforma operada por el D. Leg. 17 enero 2003 núm. 6, admite la transformación heterogénea de sociedades de capital en sociedades cooperativas (art. 2500-septies), pero no la transformación de cooperativas prevalentemente mutualistas en sociedades (art. 2545-decies).

17 Entre esas garantías puede citarse, que la decisión de transformación sea acordada en junta general por los socios, con los requisitos y formalidades exigidos para los acuerdos de especial relevancia; que se publicite debidamente el acuerdo; que se reconozca a los socios disidentes el derecho de separación; que se reconozca a los socios que continúan en la sociedad transformada una participación en el capital social proporcional a la que tenían anteriormente; que los socios que tenían responsabilidad ilimitada sigan respondiendo solidaria y personalmente con todos sus bienes de las deudas contraídas con anterioridad, salvo expreso consentimiento de los acreedores, etc. 
a vincular al socio con la cooperativa es esencial y prevalente. Los derechos del socio vendrán determinados principalmente por el desarrollo de esa participación económica y no por su aportación a capital. Por ello, el art. 69.1 Ley 27/1999 establece como requisito para transformarse en cooperativa que los miembros de las entidades a transformar «puedan asumir la posición de cooperadores en relación con el objeto social previsto para la entidad resultante de la transformación». Aquellos miembros que no puedan asumir dicha posición podrán continuar en la cooperativa en condición de socio colaborador o aso-

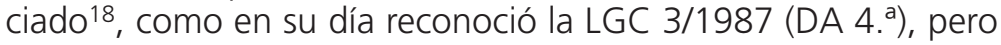
debe tenerse en cuenta que tanto su número como su participación en la cooperativa debe ser minoritaria.

Contrariamente, si la cooperativa se transforma en sociedad mercantil, los socios dejan de tener derecho a participar en la actividad económica de la sociedad, su relación se transforma en la de un mero trabajador, cliente o proveedor de la sociedad, sin ningún tipo de ventaja o garantía de que la sociedad atienda sus necesidades o aspiraciones económicas.

La actividad que la cooperativa realiza con el socio sin ánimo de lucro (con derecho al retorno en caso de generar beneficios), se transforma en lucrativa cuando se realiza por la sociedad mercantil (el socio no tiene derecho a retornos, en cambio, tendrá derecho al reparto de beneficios vía dividendos o en todo caso, a la revalorización de su aportación a capital).

En definitiva, en la sociedad mercantil lo relevante es la aportación a capital del socio, mientras que en la cooperativa es su condición de trabajador, consumidor o proveedor. La sociedad mercantil trabaja para mejorar la inversión del capital, mientras que la cooperativa trabaja para mejorar la calidad y el precio de la prestación al socio.

b) La aportación a capital que en la sociedad mercantil suele ser la medida de los derechos políticos y económicos del socio, pierde relevancia en la cooperativa, donde ni siquiera existe el derecho legal a la retribución por el capital aportado, y cuando se reconoce, su retribución no puede superar ciertos límites legales.

18 La Ley 27/1999 describe al socio colaborador como aquella persona física o jurídica, que, sin poder desarrollar o participar en la actividad cooperativizada propia del objeto social de la cooperativa, puede contribuir a su consecución (art. 14). Figuras similares al socio colaborador puede encontrarse en la legislación cooperativa con otras denominaciones, como la de asociado (art. 28 LCCV 8/2003) 
c) En la cooperativa rige el principio democrático, lo que significa que cada socio tiene derecho a un voto, mientras que en las sociedades mercantiles el voto suele ser plutocrático, o en todo caso, no rige el voto democrático.

d) En la cooperativa, cuando el socio quiere separarse no está sometido a más condicionantes que el preaviso, y tiene derecho a recuperar la aportación a capital realizada, dada la naturaleza variable de su capital; mientras que en las sociedades mercantiles, el socio sólo puede separarse si concurre alguna de las causas legal o estatutariamente establecidas o si consigue transmitir sus acciones o participaciones. En cambio, en caso de separación, tiene derecho a recuperar el valor real y no sólo nominal de su aportación a capital.

e) Por otra parte, como consecuencia de la naturaleza no lucrativa de la cooperativa, los beneficios obtenidos, o se retornan al socio que los ha generado o se aplican a fondos irrepartibles (Fondo de Reserva Obligatorio y Fondo de Educación y Promoción) como es característico de las sociedades de base mutualista. Estos fondos, que contribuyen al fortalecimiento empresarial de la cooperativa, y hacen posible el principio de puertas abiertas y de formación, información y promoción cooperativa, han sido generados gracias al esfuerzo colectivo de todos los socios que han pasado por la cooperativa, y que al separarse han dejado parte de los beneficios que han generado. La transformación de la cooperativa plantea el problema de determinar qué destino debe darse a estos fondos.

f) Además, y como consecuencia de las anteriores características de la cooperativa, esta empresa suele ser objeto de un tratamiento fiscal específico. Ese tratamiento viene condicionado entre otros factores, por la existencia de dotaciones a dichos fondos irrepartibles, por la imposibilidad de su reparto o por la correcta aplicación de los mismos a los fines legalmente establecidos (art. 13 Ley 20/1990, de Régimen Fiscal de las Cooperativas). En sede de transformación, es discutible que una entidad que ha recibido ayudas o contribuciones públicas pueda posteriormente transformarse en una sociedad lucrativa o al menos, poder aprovecharse sus socios individualmente de esas ventajas ${ }^{19}$.

19 El Código civil italiano, no admite la transformación de asociaciones que hayan recibido ayudas públicas o contribuciones de tal carácter; y tampoco permite la transformación de fundaciones, salvo por decisión de la autoridad gubernativa a propuesta del órgano competente (art. 2500-octies). 
Las modificaciones que se operan con ocasión de la transformación heterogénea son tan importantes que no puede calificarse ésta como un mero cambio de vestidura jurídica ${ }^{20}$, pues afecta a la causa misma del contrato societario. Sobre este tema Alberto Díaz analiza los distintos supuestos de transformación contemplados en la LSRL, y llega a la conclusión de que la transformación entre sociedades civiles y mercantiles debe ser perfectamente admisible puesto que comparten el ánimo de lucro como elemento causal identificador, y por tanto la intención de los socios, su propósito último cuando entraron en la sociedad, permanece idéntico, lo que cambia es el instrumento organizativo que va a utilizarse para conseguirlo. Más discutible es en cambio, en su opinión, la transformación de y en cooperativas o mutuas, porque son entidades con causas distintas: fin lucrativo versus fin mutualista ${ }^{21}$. Precisamente esta diferenciación en los fines es la razón que justifica la prohibición en la legislación portuguesa, de la transformación de la cooperativa en sociedad comercial y viceversa22.

Por ello, en estos casos, se dice que la transformación no puede ser vista como la posibilidad de buscar el mismo propósito o fin con tipos distintos, sino como la posibilidad de alterar el fin y, correlativamente el tipo, sin someterse a la regla de la unanimidad o sin disolución y posterior constitución de ente distinto.

El reconocimiento de la posibilidad de transformación entre entidades diferentes no sólo por la forma sino también por sus fines, lleva a reconsiderar la idoneidad del término «transformación», para definir estos procesos; que obedecerían más bien a una «transubstanciación» ${ }^{23}$.

Sin embargo, debe tenerse en cuenta también que cuando se plantea una transformación heterogénea, muy probablemente, los socios de la entidad a transformar lo que persiguen es adoptar un tipo societario más adecuado a sus fines. No es extraño pensar en una cooperativa inicialmente mutualista que con el tiempo ha ido perdiendo ese carácter y ha ido adquiriendo fines lucrativos, y que lleva a cabo o está

20 Alfonso Sánchez, R.: La transformación de la sociedad cooperativa, Editoriales de Derecho Reunidas, SA, 2002, p. 28.

21 Díaz Moreno, A.: «La disciplina de la transformación en el Proyecto de Ley de Sociedades de Responsabilidad Limitada», Estudios en Homenaje al profesor Broseta, t. 1, Valencia, 1995, pp., 830-833.

22 Rodrigues, J.A.: Código Cooperativo. Anotado he comentado, e Legislaçao Cooperativa, Quid luris, Lisboa, 2001, pp. 174-175.

23 Término empleado por Olivencia en relación con la transformación de asociación en sociedad (prólogo al libro de Selva Sánchez: Sociedades anónimas deportivas, Madrid, 1992, p. 16), y por Díaz Moreno, A., en relación con la transformación de y en cooperativa («La disciplina ...», op. cit., p. 832). 
interesada en llevar a cabo comportamientos sancionados por la legislación cooperativa con la pérdida de la condición de cooperativa fiscalmente protegida (art. 13 LRF 20/1990), o con la descalificación como cooperativa (art. 116 LC 27/1999)24. Este es el supuesto previsto en la legislación cooperativa italiana, al permitir la transformación en sociedad, solamente a las cooperativas que no tienen naturaleza prevalentemente mutualista25.

El legislador español, a pesar de la problemática que entraña la transformación heterogénea, ha optado por reconocer la transformación de sociedades en cooperativas y viceversa, pero ha sometido la misma a ciertas garantías en interés de los socios y terceros, como veremos a continuación.

\section{Régimen jurídico aplicable a la transformación de cooperativas}

Para dar respuesta a este tema, debemos plantearnos en primer lugar, cual es el marco normativo aplicable al supuesto de transformación de cooperativas.

Hasta el momento, la legislación cooperativa, estatal y autonómica, ha venido regulando la transformación de las cooperativas. Tras la aprobación de la LME cabe plantearse si aquél régimen ha sido modificado por la nueva ley.

En principio, su disposición derogatoria afecta al Texto Refundido de la Ley de sociedades anónimas, a la Ley de sociedades de responsabilidad limitada y a la Ley de agrupaciones de interés económico, y sus disposiciones finales introducen modificaciones además, en la Ley 31/2006 sobre implicación de los trabajadores en la SAE y SCE, y en la Ley de cooperativas de crédito 13/1989. La LME no viene a derogar ni a modificar, al menos expresamente la legislación cooperativa, a excepción de la norma de la LCC objeto de nuestro estudio.

24 De hecho, en ocasiones, la legislación cooperativa ha contemplado la transformación de la cooperativa como solución cuando su funcionamiento no se ha adaptado a los fines cooperativos. Véase en este sentido la Ley de Cooperación de 1942 (DT 6. ${ }^{\text {a) }}$ o la Ley de Cooperativas de la Comunidad Valenciana 8/2003 (art. 121.2).

25 Las cooperativas de mutualidad prevalente son aquellas que desarrollan su actividad económica principalmente con sus socios y prevén en sus estatutos las siguientes normas: la prohibición de distribuir los dividendos o remunerar los instrumentos financieros, por importe superior al legamente previsto; la prohibición de distribuir las reservas entre los socios cooperadores; o la obligación de destinar los fondos mutuales a la promoción y desarrollo de la cooperación (arts. 2513 y 1514 Codice civile). 
La Ley 3/2009 tiene por objeto, como su título indica, las modificaciones estructurales de las sociedades mercantiles, no afectando por tanto a las cooperativas ${ }^{26}$. Sin embargo, en materia de transformación, además de unificar la normativa sobre transformación de sociedades mercantiles, cuyo régimen - según dice la exposición de motivos- se encuentra dividido actualmente entre la LSA y la LSRL, "dilata el perímetro de las transformaciones posibles» afectando también a las cooperativas.

Así, el art. 7 de la LME establece, bajo el título de «Transformación de sociedades cooperativas» que la transformación de una sociedad cooperativa en otro tipo social o de éste en aquélla, se regirá en lo referente a los requisitos y efectos de la transformación de la sociedad cooperativa por la legislación que le sea aplicable ${ }^{27}$.

26 A pesar de esta evidencia, no podemos pasar por alto, el art. 2 de la LME que situado entre las disposiciones generales y bajo el título de ámbito subjetivo de aplicación de la ley señala, en primer lugar, que la presente ley es aplicable a todas las sociedades que tengan la consideración de mercantiles, bien por la naturaleza de su objeto, bien por la forma de su constitución; y en segundo lugar, que las modificaciones estructurales de las sociedades cooperativas, así como el traslado internacional de su domicilio social, se regirán por su específico régimen legal. Este precepto puede calificarse de innecesario - como hizo la Comisión General de Codificación-: es «innecesario decir dónde y cómo se regulan las cooperativas». Este párrafo 2..$^{\circ}$ del art. 2 tiene su origen en la enmienda núm. 3 del GP Vasco del Congreso de los Diputados, enmienda que no fue aceptada en los términos planteados, pero con la que se pretendía dejar clara la exclusión de las cooperativas, en respuesta al comentario hecho por el Consejo de Estado. Este órgano, en su Dictamen de 19 de diciembre de 2007 al Anteproyecto de LME de las sociedades mercantiles, concretamente en su Consideración núm. 8 criticaba que se remitiese en materia de transformación de sociedades cooperativas a su legislación aplicable, porque entendía que nada añadía, y sugería que la proyectada nueva ley podría incluir las previsiones de índole general aplicables a las transformaciones societarias que afecten a las sociedades cooperativas. En respuesta a esta posible afectación de la LME al régimen aplicable a la transformación de las cooperativas, actualmente contenido en la legislación cooperativa, responde la enmienda planteada y el texto que finalmente quedó reflejado en el art. 2.2 de la LME. La razón de su existencia no es causa que justifique la misma, y como era de esperar, introduce más confusión que aclaración. Algún autor incluso, llega a ver en esta norma la voluntad del legislador de considerar la cooperativa como una sociedad mercantil aunque dotada de un régimen específico de modificaciones estructurales (Sánchez Álvarez: «La ley de modificaciones estructurales y el concepto de modificación estructural», Modificaciones estructurales de las sociedades mercantiles; Fernando Rodríguez Artigas (dir.), Alberto Alonso Ureba (dir.), Luis Fernández de la Gándara (dir.), Luis Antonio Velasco San Pedro (dir.), Jesús Quijano González (dir.), Gaudencio Esteban Velasco (dir.), vol. 1, 2009, p. 61).

27 El segundo párrafo, que no es objeto de nuestra atención en esta sede, se refiere a la transformación de sociedades cooperativas en sociedades cooperativas europeas y viceversa, y dice que esta modificación se regirá por lo dispuesto en el Reglamento (CE) número 1435/2003 y por las normas que lo desarrollan. 
La norma plantea la duda de si la transformación en la que participe una cooperativa debe regirse por su normativa específica o si la referencia a los requisitos y efectos significa que, salvo en estas materias, regirá la $\mathrm{LME}$. La doctrina se ha pronunciado en sentidos diversos. Para Sánchez Álvarez ${ }^{28}$ la transformación de la sociedad cooperativa se regirá en cuanto a los requisitos y efectos por la legislación que le sea aplicable, y cita el art. 68 LC 27/99; pero en el procedimiento «parece que debiera aplicarse el Título I LME». Sacristán Represa también se plantea la duda pero se inclina finalmente por interpretar que el art. 7 excluye el alcance de la LME y además lo justifica ${ }^{29}$. Por último, podemos citar la opinión de León Sanz ${ }^{30}$, quien interpreta que la regulación del procedimiento se descompone entre lo dispuesto en la LME en los aspectos relativos a las sociedades mercantiles y lo dispuesto en la legislación cooperativa, en lo referente a las cooperativas. Aquellos autores que se han ocupado de estudiar cual sería el régimen aplicable a la transformación con participación de cooperativas, tras la LME, hacen un análisis integrador de las normas cooperativas y de la $\mathrm{LME}^{31}$.

Una simple lectura de los preceptos contenidos en la LME relativos a la transformación (arts. 3 a 21) pone de manifiesto claramente

28 Sánchez Álvarez: «La ley de modificaciones...», op. cit., p. 62.

29 Sacristán Represa: «Transformación de sociedad anónima en otros tipos sociales», Modificaciones estructurales de las sociedades mercantiles; Fernando Rodríguez Artigas (dir.), Alberto Alonso Ureba (dir.), Luis Fernández de la Gándara (dir.), Luis Antonio Velasco San Pedro (dir.), Jesús Quijano Gonzáles (dir.), Gaudencio Esteban Velasco (dir.), vol. 1, pp. 135-248, 2009, p. 181. Para este autor, parece razonable que se excluya la aplicación de la LME en la transformación que implica a la cooperativa teniendo en cuenta que dadas «las particularidades de ambas figuras societarias, por distintas razones, nos llevan a la necesidad de exigir que cuando otra se transforma en alguna de ellas adopte previamente o en el curso de la transformación condiciones exigidas por esa peculiaridad, que no tienen correspondencia en la que se producen entre tipos mercantiles de sociedad de cuño nacional. A esos requisitos no hace referencia la LME, sino que... con mayor o menor claridad vienen establecidas en esa legislación peculiar a la que con distinta amplitud en ambos preceptos se hace referencia».

30 León Sanz: "Los antecedentes y los aspectos generales de la transformación», Modificaciones estructurales de las sociedades mercantiles; Fernando Rodríguez Artigas (dir.), Alberto Alonso Ureba (dir.), Luis Fernández de la Gándara (dir.), Luis Antonio Velasco San Pedro (dir.), Jesús Quijano Gonzáles (dir.), Gaudencio Esteban Velasco (dir.), vol 1, 2009, p. 118.

31 Peñas Moyano: «Transformación de sociedades cooperativas (cooperativa nacional y cooperativa europea)», Modificaciones estructurales de las sociedades mercantiles; Fernando Rodríguez Artigas (dir.), Alberto Alonso Ureba (dir.), Luis Fernández de la Gándara (dir.), Luis Antonio Velasco San Pedro (dir.), Jesús Quijano González (dir.), Gaudencio Esteban Velasco (dir.), vol. 1, 2009, pp. 261 y ss., y Ávila Navarro, P.: Modificaciones estructurales de las sociedades mercantiles. Ley 3/2009, t. I, Bosch, Barcelona, 2009, pp. 243 y ss. 
que el legislador no tiene en mente la participación de una cooperativa en el proceso de transformación, porque no recoge peculiaridades que le son propias (v.gr. cumplimiento de requisitos para ser cooperadores, destino de reservas irrepartibles, etc.), ni tampoco el régimen previsto en la LME es compatible con el que exigiría la transformación de/ en cooperativas (v. gr. ejercicio derecho de separación, publicación del acuerdo en $\mathrm{BOE}$, situación del socio industrial que desarrollaría su trabajo en la cooperativa como prestación accesoria, en lugar de cómo socio de trabajo, que es lo propio, etc.); y que sí contempla la legislación cooperativa.

Entendemos que la LME ha incidido en el régimen aplicable a la transformación de/en cooperativas muy tangencialmente, a excepción del caso de las cooperativas de crédito que veremos a continuación:

a) La ampliación del perímetro subjetivo que anuncia la exposición de motivos, más allá de la regulación de las modificaciones estructurales de las sociedades mercantiles en materia de transformación, debe limitarse - por lo que a las cooperativas se refiere- al reconocimiento de la transformación de éstas en sociedades mercantiles y viceversa; es decir, a los supuestos posibles previstos en el art. 4. Que indudablemente, no constituye una novedad porque ya la legislación cooperativa contemplaba esos supuestos y más, en el art. 69.1 LC 27/99, pero sí constituye una novedad desde el punto de vista de la regulación de la sociedad anónima 32 .

b) La remisión que el art. 7 hace a la regulación de los requisitos y efectos de la transformación conforme a la legislación aplicable a las cooperativas, no puede interpretarse como que el procedimiento aplicable será el previsto en la $L M E$, porque la regulación de éste no se ha hecho pensando en las cooperativas y no es un régimen adecuado para el caso.

c) Entendemos por tanto, que la normativa aplicable a la transformación de/en cooperativas es la contenida en la legislación cooperativa, sin perjuicio de la aplicación analógica que pudiera hacerse de algunas normas de la $\mathrm{LME}^{33}$.

32 Porque recordamos que la LSRL sí contemplaba la transformación de/en cooperativa, pero no el Texto refundido de la ley de sociedades anónimas.

33 La aplicación analógica de las normas de la LME a supuestos de transformación de/en cooperativas no debe plantear problemas si se hace conforme prevé el art. 4.1.C.c. Es un tema recurrente en materia de transformación plantear la procedencia o no de la aplicación analógica de las normas. Entendemos que la transformación, como mecanismo que permite un cambio sustancial en la estructura y regulación de una 
d) La anterior conclusión no excluye una valoración crítica de sus consecuencias, en el sentido de que hubiera sido deseable que se hubiera regulado un régimen común aplicable a todo supuesto de transformación, o al menos, que hubiera incluido a las cooperativas, y haber previsto o haber remitido a otros textos, los aspectos específicos que según el tipo social partícipe fueran necesarios, como se hizo en la UmwG alemana de 1994, y que algunos autores reclamaban ${ }^{34}$. En cualquier caso, es previsible, que en futuras reformas de la legislación cooperativa, se opte, como se ha hecho en tantas ocasiones, por hacer una remisión a la aplicación del régimen previsto en esta ley, salvo en aquellos aspectos que regule específicamente la legislación cooperativa.

Como consecuencia, cabe decir que el marco normativo aplicable a la transformación de la cooperativa será el previsto en la legislación cooperativa, y por tanto, la primera tarea será determinar qué ley de cooperativas es la aplicable. A tales efectos habrá que tener en cuenta que el ámbito de aplicación de las diversas leyes de cooperativas viene determinado por el ámbito de actuación de la cooperativa con sus propios socios, lo que se conoce cómo ámbito de su actividad cooperativizada.

Así, la LC 27/1999 se aplica a las cooperativas que desarrollen su actividad cooperativizada en el territorio de varias CCAA, excepto cuando en una de ellas se desarrolle con carácter principal; y también se aplica a las cooperativas que realicen principalmente su actividad cooperativizada en las ciudades de Ceuta y Melilla (art. 2).

Además, y como excepción a la anterior norma, debe tenerse en cuenta que el criterio para determinar la competencia en materia de cooperativas cambia en el caso de las cooperativas de crédito. Tras la aprobación de la LC 27/99, se publicó la Ley 55/1999, de 29 de diciembre, de Medidas Administrativas, Fiscales y de Orden Social (art. 54), que vino a dar una nueva redacción al recién aprobado art. 104 LC, en el siguiente sentido: "Las cooperativas de crédito se regirán por su ley específica y por sus normas de desarrollo. Asimismo, les serán de apli-

sociedad, que trae importantes consecuencias para socios y terceros, no debe ser posible por la mera voluntad de los socios, sino que requiere estar prevista en la ley su admisión y las garantías que lo hagan posible sin defraudar los derechos de los sujetos implicados. Y en este caso, la transformación de/en cooperativa está admitida y regulada en la ley, la aplicación analógica de la LME que defendemos, sólo tendría por objetivo completar las lagunas que el régimen previsto en la legislación cooperativa pudiera plantear.

34 Vicent Chuliá, F.: «Reforma del régimen...», op. cit., pp. 66 y ss. 
cación las normas que, con carácter general, regulan la actividad de las entidades de crédito, y con carácter supletorio la presente Ley de Cooperativas cuando su ámbito de actuación estatutariamente reconocido, conforme a su ley específica, sea supraautonómico o estatal, siempre que realicen en el citado ámbito actividad cooperativizada de manera efectiva». Como puede verse, en el caso de las cooperativas de crédito, se aplicará en primer lugar su legislación específica (Ley 13/1989 de Cooperativas de crédito y su Reglamento, aprobado por RD 84/1993) y supletoriamente la LC 27/99 siempre que su actividad cooperativizada exceda de una Comunidad Autónoma ${ }^{35}$.

Todas las leyes de cooperativas, tanto la estatal como las autonómicas han regulado la transformación con participación de las cooperativas $^{36}$. En nuestro análisis vamos a limitarnos a la regulación contemplada en la ley 27/1999, concretamente en su art. 69 que lleva por título: «Transformación».

Según este precepto, cualquier asociación o sociedad que no tenga carácter cooperativo y las agrupaciones de interés económico, podrán transformarse en cooperativa, y éstas podrán transformarse en sociedades civiles o mercantiles de cualquier clase, sin que se vea afectada la personalidad jurídica de la entidad transformada.

La norma regula a continuación el procedimiento que debe seguirse para la transformación de la cooperativa, y algunos requisitos que deberán cumplirse para la transformación en cooperativa.

Entre estos últimos, la Ley exige que la entidad que se transforma cumpla la legislación sectorial que sea aplicable al tipo de cooperativa en que va a transformarse (cooperativa de crédito, de seguros, de transporte, de enseñanza, etc.); que sus miembros puedan asumir la posición de cooperadores en relación con el objeto social previsto; que la transformación se formalice en escritura pública, y que contenga las menciones exigidas en la legislación aplicable a la entidad que se transforma (art. 18.2 LME y art. 222 RRM); que si estuviera inscrita en el RM, el Registrador haga constar la inexistencia de obstáculos para la

35 Esta norma que reduce las competencias de las CCAA en la regulación de las cooperativas de crédito, fue recurrida en su momento y declarada constitucional por el TC (Sala Pleno) en sentencia núm. 291/2005, de 10 de noviembre.

36 Esta regulación está prevista en: ley andaluza 2/99 (arts. 108-109); ley catalana 18/02 (art. 84-85); ley vasca 4/93 (arts. 85-86); ley valenciana 8/03 (arts. 79-80); ley navarra 14/06 (art. 59); ley aragonesa 9/98 (art. 66); ley castellano leonesa 4/02 (arts. 86 y 89); ley castellano-la mancha 20/02 (arts. 79-80); ley extremeña 2/98 (arts. 74 a 81); ley gallega 5/98 (arts. 84-85); ley riojana 4/01 (arts. 91-92); ley madrileña 4/99 (arts. 83 a 92) y ley murciana (8/06 (arts. 94-95). Como excepción, la transformación no está regulada en la Ley de Cooperativas de las Islas Baleares 1/2003. 
transformación, y finalmente, que si la entidad a transformar tuviera socios que respondieran personalmente de las deudas contraídas por la entidad, la transformación no liberará a estos socios de su responsabilidad por las deudas contraídas por ésta con anterioridad a la transformación, salvo consentimiento expreso a la transformación de los acreedores.

La regulación del procedimiento de transformación de la cooperativa comienza con los requisitos que debe cumplir el acuerdo de transformación (adopción por asamblea general con las formalidades legales previstas para la convocatoria y constitución de la misma. La remisión que hace el art. 69 LC a los requisitos exigidos para la adopción del acuerdo de fusión, obliga a interpretar los arts. 63.7 y 64, con el fin de adaptarlos al supuesto de transformación, y el resultado no es muy satisfactorio, sobre todo en cuanto a la información económica que debe procurarse al socio, por lo que sería conveniente integrar la interpretación de esta norma con lo preceptuado en el art. 9 de la LME.

A continuación, el art. 69 LC hace referencia al derecho de separación del socio disconforme, a la participación de los socios en la sociedad transformada, a su responsabilidad y al destino de los fondos irrepartibles.

En relación con el derecho de separación de los socios ${ }^{37}$, se reconoce «en los términos previstos para el caso de fusión», por lo que es un derecho reconocido a los socios que no votaron a favor del acuerdo de transformación, y que se ejercita comunicando la baja por escrito al Presidente del Consejo rector, en el plazo de 40 días desde la publicación del anuncio del acuerdo de transformación (art. 65). El socio que causa baja de la cooperativa tiene derecho al reembolso de sus aportaciones al capital social, liquidadas conforme establece el art. 51 para el caso de baja justificada, que deberá hacerse efectivo en el plazo

37 La regulación del derecho de separación en la legislación cooperativa ha sufrido una evolución, consecuencia del mimetismo seguido por el legislador al regular esta materia. Así, es propio de la cooperativa que el socio pueda causar baja en cualquier momento, sin necesidad de manifestar causa para ello; este derecho es consecuencia del principio de adhesión voluntaria y abierta que caracteriza a estas entidades. Hasta la LGC 1987, la legislación cooperativa, hacía referencia a la baja del socio con ocasión de la fusión, con el fin de calificar la misma como justificada a los efectos de su liquidación, impidiendo que se la aplicaran deducciones o aplazamientos a su reembolso. Sin embargo, a partir de la citada ley, y seguramente, por influencia de la entonces proyectada reforma de la Ley de Sociedades de Responsabilidad Limitada por Ley 19/1989, se incorpora una expresa referencia al derecho de separación del socio como si fuese un derecho generado a raíz de su disconformidad con el acuerdo adoptado, como ocurre en la $\mathrm{SRL}$, cuando en la cooperativa sigue siendo un derecho que tiene el socio en cualquier momento. 
máximo de cinco años. Esta cantidad no podrá actualizarse pero dará derecho al cobro del interés legal del dinero, que deberá abonarse anualmente junto con, al menos, una quinta parte de la cantidad a reembolsar.

Otro requisito que deberá cumplirse en el proceso de transformación es que la participación de los socios de la cooperativa en el capital social de la nueva entidad sea proporcional al que tenían en aquella. La norma, inspirada en la LSA (art. 229) parece responder al principio de continuidad en la participación, tan propio de las sociedades capitalistas pero que causa extrañeza en un régimen cooperativo. Así la doctrina ha criticado que sea la propia ley cooperativa la que utilice un criterio capitalista para indicar la participación de los socios en el capital social de la sociedad transformada, en lugar de utilizar otros criterios más cooperativos como la igualdad o la medida en que los socios vienen participando en la actividad cooperativizada. En este sentido, Nagore se muestra más partidario del uso de un criterio mixto que tomase en consideración tanto el derecho de voto (democrático) como el derecho a participar en los resultados económicos (en proporción a la participación en la actividad económica). En todo caso, recomienda que con carácter previo a la transformación, se reorganicen las aportaciones de los socios en aras a mantener dicha proporcionalidad usando la normativa cooperativa ${ }^{38}$.

También se preocupa la ley de cooperativas de establecer que aquellos socios que como consecuencia de la transformación pasen a responder personalmente de las deudas sociales, responderán de igual forma de las deudas anteriores de la sociedad cooperativa. La norma, presente también en la regulación de las sociedades mercantiles (art. $21 \mathrm{LME}$ ), tienen como objetivo proteger a los anteriores acreedores y evitar la diferenciación entre acreedores anteriores al proceso y acreedores posteriores.

Por último, señala el art. 69. 9 LC que en el supuesto de transformación de una sociedad cooperativa en otro tipo de entidad, los saldos de los fondos de reserva obligatorio, el fondo de educación y cualesquiera otro fondo o reservas que estatutariamente no sean repartibles entre los socios, recibirán el destino previsto en el art. 75 de esta Ley para el caso de liquidación de la cooperativa. Según este precepto, el

38 Nagore, I.: «Tratamiento del capital social en la transformación de las cooperativas», Boletín de la Asociación Internacional de Derecho Cooperativo, Universidad de Deusto, Bilbao, 2001, pp. 47-50, y en el mismo sentido, Paniagua Zurera, M.: La sociedad cooperativa. Las sociedades mutuas de seguros y las mutualidades de previsión social, Tratado de Derecho Mercantil, t. 12, vol. 1, Marcial Pons, Madrid, 2005, p. 318. 
fondo de educación y promoción, que tiene como objetivo la formación y educación de los socios y trabajadores; la difusión del cooperativismo y la promoción cultural, profesional y asistencial del entorno o de la comunidad en general, se pondrá a disposición de la entidad federativa a la que esté asociada la cooperativa o a la que designe la Asamblea General, y en su defecto, su importe se ingresará en la Confederación estatal de cooperativas de la clase correspondiente o en el Tesoro Público. Los demás fondos, una vez liquidados conforme establece el art. 75 se destinarán a la cooperativa o sociedad federativa que figure expresamente en los Estatutos o se designe por la Asamblea, y en su defecto se ingresara el importe como en el caso anterior, en la Confederación estatal de cooperativas de la clase correspondiente o en el Tesoro Público.

La irrepartibilidad de estos fondos - como ya vimos- es una característica de las cooperativas y en general de todas las entidades no lucrativas y de base mutualista. Representan el patrimonio colectivo generado por todos los socios y puesto a disposición del desarrollo de la cooperativa más allá de su permanencia en la misma. En el caso de las asociaciones, la legislación no permite la distribución de su patrimonio entre los asociados en caso de disolución de la asociación ${ }^{39}$. En el caso de las entidades de base mutualista, el patrimonio es irrepartible en caso de baja del socio, pero sí puede distribuirse en caso de disolución de la entidad ${ }^{40}$. En la legislación cooperativa el patrimonio irrepartible lo es tanto en el momento del reembolso al socio que causa baja como en caso de disolución y liquidación de la cooperativa. Como dice la Declaración de la Alianza Cooperativa Internacional en su Declaración de Manchester de 1995 en relación con el Tercer Principio Cooperativo: Participación Económica de los socios, «cuando prosperan las cooperativas podrán crear reservas, derivadas de las ganancias retenidas de las

39 El art. 17.2 LO del Derecho de Asociación 1/2002 prevé que en caso de disolución se dará al patrimonio de la asociación el destino previsto en los estatutos sociales; y el art. 7 al enunciar el contenido de éstos señala que deberán indicar su destino en dicho caso «que no podrá desvirtuar el carácter no lucrativo de la entidad».

40 Así por ejemplo, la Ley de SGR 1/94 al regular el derecho al reembolso de las participaciones, establece que el importe der reembolso no podrá exceder del valor real de las participaciones aportadas ni de su valor nominal, la eventual plusvalía pertenecerá a las reservas de la sociedad, sobre las cuales no tiene derecho alguno el socio que obtiene el reembolso (art. 29.3); mientras que en caso de disolución de la sociedad y reparto del activo resultante de la liquidación, establece que éste se distribuirá entre los socios en proporción al número de participaciones de las que sean titulares, pudiendo excluir los estatutos la participación en este reparto de los socios que lo hayan sido por un plazo inferior a cinco años (art. 62). 
actividades de la organización. Normalmente, todas o una proporción bastante grande de estas ganancias son de propiedad colectiva, representando los logros colectivos de los socios en apoyo de su cooperativa. En muchas jurisdicciones este capital «colectivo» no se distribuye entre los socios si la cooperativa deja de existir, en su lugar, se distribuye entre empresas comunitarias u otras cooperativas asociadas ${ }^{41}$.

La irrepartibilidad de estas reservas, siempre ha estado prevista en la legislación cooperativa en caso de transformación, aunque se le hayan podido dar distintos destinos. Y esa característica también fue tenida en cuenta por la LSRL y el RRM al regular la transformación de cooperativas $^{42}$.

Por último y para completar el régimen jurídico aplicable a la transformación de la cooperativa habrá que tener en cuenta la aplicación de otras disposiciones que regulen la transformación desde el punto

41 En Alemania, como dice el § 92 de la Ley de Cooperativas de 1889, «Activo neto irrepartible», el activo neto irrepartible que existiera en el momento de la disolución de la cooperativa revertirá al municipio en cuyo término tuviera aquella su sede a menos que los Estatutos lo atribuyeran a favor de otra persona física o jurídica en razón de una finalidad determinada. Los intereses de estos fondos habrán de destinarse a fines de utilidad pública. En Francia, la Ley 47/1775, de 10 de septiembre que aprueba el Estatuto General de la Cooperación, en su art. 19 establece que en caso de disolución y sin perjuicio de lo dispuesto en leyes especiales, el activo neto que restara tras enjugar el pasivo y el reintegro del capital efectivamente aportado, se destinará, mediando acuerdo de la asamblea general, bien a otras cooperativas o uniones de cooperativas, bien a fines de interés general o profesional. En Portugal, el Código Cooperativo aprobado por Ley 51/1996 establece en su art. 79 «Destino del patrimonio en liquidación» que el montante de la reserva legal que no se haya destinado a cubrir pérdidas y no sea susceptible de otra aplicación, podrá ser transferido con idéntica finalidad a la nueva entidad cooperativa que se forme como consecuencia de la fusión o escisión de la cooperativa en liquidación. Cuando a la cooperativa en liquidación no suceda ninguna entidad cooperativa nueva, la aplicación del saldo de reservas obligatorias revertirá a otra cooperativa, preferentemente del mismo municipio, a determinar por la federación o confederación representativa de la actividad principal de la cooperativa. La legislación cooperativa italiana (arts. 2511 y ss. Codice civile) también contempla la existencia de reservas indivisibles, que no pueden ser repartidas entre los socios, ni siquiera encaso de disolución de la sociedad (art. 2545-ter), y contempla expresamente esta indivisibilidad en el caso de transformación de cooperativa (art. 2545-undecies), aunque sólo permite la transformación a las cooperativas de mutualidad no prevalente.

42 Según el art. 93.3.b LSRL, en defecto de norma específicamente aplicable, el Fondo de Reserva Obligatorio, el Fondo de Educación y Promoción y cualesquiera otros Fondos o Reservas que no sean repartibles entre los socios, recibirán el destino establecido para el caso de disolución de las sociedades cooperativas. El art. 218.2 del RRM por su parte establece que, en caso de transformación de cooperativa, en la escritura se expresarán también las normas que han sido aplicadas para la adopción del acuerdo de transformación, así como el destino que se haya dado a los fondos o reservas que tuviere la entidad. 
de vista de la sociedad transformada, como el art. 93 LSRL y el art. 218 RRM que, para el caso de transformación en SRL exige que en la escritura se incluya la manifestación de los otorgantes, bajo su responsabilidad, de que el patrimonio cubre el capital social quedando éste totalmente desembolsado, y que junto a la escritura de transformación se presente para su depósito en el RM un balance general de la cooperativa cerrado el día anterior al del acuerdo de transformación; la certificación del Registro de cooperativas en la que conste la declaración de inexistencia de obstáculos para la inscripción de la transformación; y copia del BOE y del diario de gran circulación en la provincia del domicilio social donde se haya publicado, conforme establece el art. 64.2 LC, el acuerdo de transformación.

Por último, y aplicando las normas que regulan la constitución de la nueva sociedad transformada, habrá que proceder —en su caso- a su inscripción en el Registro correspondiente (RM). Tras esta inscripción que deberá ser notificada al Registro de Cooperativas, éste procederá a la inmediata cancelación de los asientos relativos a la cooperativa.

\section{La transformación de la cooperativa de crédito y el destino de sus reservas irrepartibles}

Como vimos en el apartado anterior, la cooperativa de crédito se rige por su legislación específica (LCC 13/1998 y RD 84/93) y supletoriamente, por la LC 27/1999, si su actividad cooperativizada excede de una Comunidad Autónoma.

También vimos al inicio de este trabajo que antes de la $L M E$, ni la LCC ni su reglamento preveían la transformación de cooperativas de crédito, pero el supuesto sí estaba contemplado tanto en la DA $4 .^{a}$ del RD 1245/95 que regulaba la autorización para transformar una entidad de crédito ya constituida, como podría ser una cooperativa de crédito, en un banco; como en la legislación cooperativa, de aplicación supletoria (v. gr. LC 27/1999).

La LME, como también adelantamos, en su DF $4 .^{\text {a }}$ ha modificado la Ley 13/1989, de Cooperativas de crédito, para dar una nueva redacción a su art. 10, e incorporar la transformación como modificación que puede afectar a una cooperativa de crédito.

Según el nuevo art. 10 la transformación que afecte a una cooperativa de crédito requerirá autorización administrativa previa, con informe del Banco de España.

Si la cooperativa de crédito es resultado de la transformación, deberá solicitar su inscripción en el Registro correspondiente del Banco 
de España, sin perjuicio de la inscripción que proceda en el Registro de Cooperativas que le corresponda.

Si por el contrario es la cooperativa de crédito la que se transforma en otra entidad de crédito, "el Fondo de Reserva Obligatorio de aquella pasará a integrarse en el capital social de la entidad resultante de la transformación».

Este precepto es resultado de la enmienda (núm. 84) presentada en su día por el GP Catalán (CiU) en la que solicitaba que los saldos del fondo de reserva obligatorio continuaran formando parte integrante del patrimonio de la entidad de crédito resultante de la transformación, sin recibir el destino previsto en el art. 75, por remisión del art. 69.9 LC, esto es, sin recibir el destino previsto para caso de disolución. El texto propuesto concluía extendiendo la aplicación de esta norma a todo supuesto de transformación, cualquiera que fuera el momento en que se hubiera realizado, siempre que la sociedad transformada fuese una entidad de crédito; es decir, retrotraía los efectos de la norma a supuestos de transformación ya ejecutada.

La propuesta se justificaba en aras de defender la máxima solvencia de la entidad resultante de la transformación con el objeto de evitar que una parte significativa de su patrimonio pase a formar parte de otra cooperativa, en lugar de integrarse en la nueva entidad bancaria. Asimismo, pretende «superar la actual discriminación que perjudica a las cooperativas de crédito que se transforman respecto de las sociedades de capital que abordan este mismo proceso ${ }^{43}$.

En la misma sesión en que se defendía la enmienda núm. 84, el representante del GP Vasco, Sr. Olabarría, destacaba el olvido de no haber contemplado también el destino del «fondo de asistencia social», en referencia al Fondo de Formación y Promoción Cooperativa ${ }^{44}$.

La citada enmienda 84 fue objeto de transacción y en el texto final aprobado en la Comisión de Justicia del Congreso con competencia legislativa plena se decía que cuando una cooperativa de crédito se transforme en otra entidad de crédito: «el Fondo de Reserva Obligato-

43 Diario de Sesiones del Congreso de los Diputados núm. 163, de 2 diciembre de 2008. Comisión de Justicia.

44 El Sr. Olabarría reivindicaba, en aras de la seguridad jurídica, la corrección de la norma propuesta para incorporar la referencia al destino de estos fondos sociales. El diputado centra su discurso en la existencia de este fondo, ante aquellos que alegan que las cooperativas de crédito no están obligadas a su constitución, por razón de su objeto social o por su condición de cooperativas de segundo grado, apreciaciones ambas erróneas, que el diputado trata de combatir, para así, reclamar la previsión de su destino en la norma (Diario de Sesiones del Congreso de los Diputados de 2 diciembre de 2008, p. 3). 
rio de aquella pasará a integrarse, con carácter indisponible, en la reserva legal de la entidad resultante de la transformación» ${ }^{45}$.

El nuevo texto concreta el destino del FRO de la cooperativa, que se integrará en la reserva legal de la entidad resultante de la transformación, pero «con carácter indisponible».

Durante la tramitación de la LME en el Senado, el texto remitido por el Congreso de los Diputados fue objeto de una enmienda del GP Popular (núm. 12) y de una enmienda transaccional basada en la anterior y presentada por los Grupos Parlamentarios Popular, Socialista, Catalán, Vasco, Mixto y la Entesa Catalana de Progrés. El texto propuesto es el que finalmente fue aprobado y que citamos al iniciar este trabajo.

Su principal novedad reside en que el FRO no pasará a integrarse con carácter indisponible en la reserva legal, sino que "pasará a integrarse en el capital social de la entidad resultante de la transformación».

La justificación de este nuevo texto la daba el senador Conde Bajén, defendiendo la enmienda núm. 12 en representación del GP Popular, en la sesión celebrada el 9 de marzo de 2009 en la Comisión de Justicia del Senado. En primer lugar hacía referencia a que si la cooperativa de crédito destina el FRO conforme prevé la legislación cooperativa para caso de transformación, se descapitaliza como entidad financiera y no podrá llegar a ser banco porque no va a poder cumplir los coeficientes de caja que exige el Banco de España, por lo que hay que buscar una solución. Pero el texto aprobado en el Congreso no le resulta muy convincente, principalmente porque favorece operaciones especulativas, como consecuencia de que el valor del capital es en las cooperativas de crédito inferior al $10 \%$ de su patrimonio, por lo que tras la transformación, es muy probable que se dieran opas.

Por ello, su grupo propone que el FRO no quede como un fondo indisponible sino formando parte de modo necesario del capital social, de manera que, en el canje, si un título participativo en la cooperativa tiene un valor de 60,40 euros, pasaría a ser una acción cuyo valor incorporaría además la parte proporcional del FRO. De esta forma, en su opinión, ya no cabría una opa por una cantidad teóricamente muy superior al valor nominal del título, sino que tendría que ser por el valor real patrimonial, lo que evitaría opas y otras operaciones especulativas.

Durante la tramitación parlamentaria de esta norma también hubieron manifestaciones en contra que finalmente no tuvieron eco, como la propuesta hecha por la Unión Nacional de Cooperativas de Crédito

45 BOCG Senado de 29 de diciembre de 2008. 
(UNACC), o la enmienda núm 9 presentada por el senador Sr. Tuñón San Martín del GP Mixto.

La UNACC ${ }^{46}$ elaboró un informe con ocasión de la tramitación de la reforma legislativa que comentamos, en el que recordaba que el FRO es el resultado del ahorro colectivo de los cooperativistas de crédito, que dedican todo el beneficio a constituir reservas, no distribuyendo retornos ni incrementando el valor de las participaciones de los socios; y por ello la ley le ha conferido siempre carácter indisponible aun en caso de disolución. El citado informe fue presentado tras la propuesta aprobada en el Congreso, según la cual el FRO se integraría, con carácter indisponible, en la reserva legal de la entidad resultante de la transformación; y proponía que se especificase el alcance de tal indisponibilidad del fondo de conformidad con los principios cooperativos ${ }^{47}$.

Por otra parte, en el trámite ante la Comisión de Justicia del Senado, el Sr. Tuñón, del GP Mixto formuló una enmienda (núm. 9) al texto aprobado en el Congreso, por la que solicitaba la eliminación del párrafo $2 .^{\circ}$ de la norma propuesta.

Esta enmienda se justifica en que las cooperativas de crédito además de entidades de crédito son cooperativas, y considera que la norma propuesta no lo tiene en cuenta. Y subraya que el destino y finalidad del FRO es un pilar básico del cooperativismo, porque tiene por objeto proteger la existencia de la cooperativa, lo que hace también que la conformación de estos fondos sea clave en el fomento de las cooperativas. Por ello afirma que la norma propuesta atenta contra los principios cooperativos y contra las normas nacionales e internacionales que regulan las cooperativas.

Desde luego, la norma que contiene el art. 10.2 LCC plantea graves problemas, no sólo porque permite atribuir un patrimonio común, conformado por muchos cooperativistas a lo largo de décadas, a unos cuantos, lo cual contradice principios básicos de nuestro ordenamiento como la justicia o la equidad; sino que supone un aliciente para que estos potenciales beneficiarios de la norma promuevan la transformación de la cooperativa de crédito, con el fin exclusivo de obtener la plusva-

46 La UNACC o Unión Nacional de Cooperativas de Crédito, es la organización representativa de este sector de las cooperativas de crédito ante las Instituciones, y agrupa a todas las cooperativas de crédito constituidas: 84 cajas rurales y 8 cooperativas populares y profesionales (http://www.unacc.com).

47 En particular la propuesta de la UNACC consistía en que el FRO «en su totalidad» se integrase con carácter indisponible, en la reserva legal de la entidad resultante de la transformación, «no pudiendo ser utilizado para ampliaciones de capital con cargo a reservas ni ser objeto de distribución o reparto entre los socios actuales o futuros de la nueva entidad o sucesoras en caso de liquidación». 
lía que les generará la transformación de su participación (valorada en 60,40 euros) en acciones, apropiándose así del patrimonio común generado por los anteriores cooperativas y por las contribuciones públicas (ayudas fiscales y de otro tipo).

Las consecuencias negativas que se derivan de esta reforma legislativa trascienden incluso del caso particular de transformación de una u otra cooperativa de crédito, y amenazan a todo el sistema del crédito cooperativo, porque combaten uno de sus puntos fuertes: su patrimonio común, el que hace posible que los cooperativistas obtengan un servicio en mejores condiciones de calidad y precio (principio de participación económica); al alcance de todos los ciudadanos (principio de puerta abierta); atendiendo sus necesidades económicas y sociales (principio de formación e información), y haciendo partícipes de sus resultados a la comunidad en la que se asientan (principio de interés por la comunidad).

A pesar de los reiterados pronunciamientos de las autoridades internacionales ${ }^{48}$ y de la UE ${ }^{49}$ en defensa de las cooperativas como elemento esencial en una economía sostenible, y en particular, de la importancia de mantener sus reservas irrepartibles con ocasión de su disolución o transformación ${ }^{50}$, lo cierto es que nuestros parlamentarios

48 Resolución de la Asamblea General de las Naciones Unidas en su 88. ${ }^{a}$ sesión plenaria, de 19.12.2001 y Recomendación de la OIT núm. 127 de 20.06.2002, sobre la Promoción de las Cooperativas; e Informe del Secretario General de Naciones Unidas de 13.07.2009 sobre Las cooperativas en el desarrollo social.

49 Comunicación de la Comisión de 23 de febrero de 2004 sobre el fomento de las cooperativas en Europa; Resoluciones del Parlamento Europeo de 11 de febrero de 1994 sobre la contribución de las cooperativas al desarrollo regional; de 18 de septiembre de 1998, sobre el papel de las cooperativas en el crecimiento del empleo de las mujeres, y de 26 de enero de 2009 sobre economía social; o Dictamen del CESE sobre Distintos tipos de empresas, de 1 de octubre de 2009. La Resolución del PE de 2009 en su consideración núm. 28 pide a la Comisión que no obstaculice las normativas nacionales en materia social y fiscal, como las destinadas a las cooperativas del sector bancario, que operan sobre la base de los principios de la mutualidad, de la democracia societaria, de la transmisión del patrimonio entre generaciones, "de la indivisibilidad de las reservas», de la solidaridad, de la ética del trabajo y de la empresa.

50 La Comunicación de la Comisión al Consejo, al Parlamento Europeo, al Comité Económico y Social Europeo y al Comité de las Regiones sobre Fomento de las Cooperativas en Europa de 2004, señala entre sus objetivos: Evitar la disolución "prematura» de las cooperativas con éxito y el pillaje de activos o las «desmutualizaciones», e invita a los Estados miembros a garantizar que, a la hora de liquidar o transformar una cooperativa, sus activos se distribuyan según el principio cooperativo de "distribución desinteresada», es decir, entre otras cooperativas en que los socios puedan participar o entre organizaciones de cooperativas con objetivos similares o de interés general. E invita a los Estados miembros a proteger los activos de las cooperativas para que, en caso de adqui- 
no han sido sensibles a los intereses del cooperativismo ni de los cooperativistas, y eso que recae sobre ellos, como poder público, el mandato constitucional de fomentar «mediante una legislación adecuada, las sociedades cooperativas» (art. 129.2 CE); y se han preocupado exclusivamente de garantizar la solvencia de las entidades de crédito, sin esforzarse por conjugar este legítimo interés con el interés de todos aquellos que a lo largo de generaciones han conformado ese patrimonio que ahora permiten repartir entre los nuevos accionistas.

Un mayor esfuerzo por encontrar una solución más integradora han venido realizando algunas Comunidades Autónomas al regular el destino de las reservas irrepartibles con ocasión de la transformación de la cooperativa. Mientras todas las leyes coinciden en que el Fondo de educación y promoción se destinará como en caso de disolución y liquidación; el destino del FRO y de cualquier otro fondo irrepartible ofrece más alternativas.

Así, la Ley vasca de cooperativas 4/1993, en su art. 85.4 establece que el valor nominal de las dotaciones a dichos fondos «se acreditará al Consejo Superior de Cooperativas de Euskadi como títulos de cuentas en participación referidos a la sociedad resultante del proceso transformador», debiendo adoptar la oportuna decisión la misma Asamblea que acuerde la transformación. Este sistema permite que dichos fondos se integren en el patrimonio de la nueva entidad, mientras que los beneficios que genere puedan seguir destinándose a la promoción del cooperativismo ${ }^{51}$.

La ley catalana de cooperativas 18/2002 en su art. 84 exige que una vez los socios hayan ejercido su derecho de separación, el patrimonio de la cooperativa que se transforma se traspase en bloque a la nueva sociedad que haya surgido, pero los estatutos o la asamblea ge-

sición y transformación de una cooperativa en sociedad anónima, se respeten estrictamente la voluntad de los socios y los objetivos de la cooperativa.

Por su parte, el Reglamento (CE) núm. 1435/2003 del Consejo, de 22 de julio de 2003, relativo al Estatuto de la SCE, al regular la adjudicación del activo como consecuencia de la disolución de la cooperativa europea, se remite al «principio de adjudicación desinteresada» (art. 75).

51 El Consejo Superior de Cooperativas de Euskadi es el máximo órgano de promoción y difusión del cooperativismo, se configura como una entidad pública de carácter consultivo y asesor de las administraciones vascas para todos los temas que afecten al cooperativismo, y entre sus funciones están: difundir los principios del movimiento cooperativo, facilitar y colaborar en la investigación, planificación y ejecución de los programas de desarrollo y fomento del cooperativismo, y promover la educación y formación cooperativa; informar los proyectos legales, colaborar con la Administración en la difusión de la ley; organizar servicios de interés común para las federaciones de cooperativas; o resolver conflictos internos por vía de arbitraje (art. 145 Ley 4/1993). 
neral al aprobar la transformación, deberán establecer «cómo se garantiza el derecho a percibir los fondos no repartibles a las entidades que tendrían que ser destinatarias de los importes», conforme a las normas sobre liquidación. En este caso, las partes tienen más libertad para decidir cómo va a reconocerse el derecho sobre dichos fondos, que se integrarán en el patrimonio de la entidad transformada.

Por último, la Ley valenciana de cooperativas 8/2003, en su art. 79.5 prevé que los estatutos o en su defecto, las partes interesadas determinarán la forma en que se acreditará a quienes sean los destinatarios del haber líquido social en caso de liquidación, el valor nominal de las dotaciones a la reserva obligatoria. La entidad resultante de la transformación y los destinatarios del haber liquido social podrán establecer de mutuo acuerdo, las condiciones en que se hará efectivo el crédito de estos últimos; en otro caso, el valor nominal de las dotaciones de la reserva obligatoria se acreditará como crédito retribuido, a un interés de tres puntos porcentual superior al interés legal del dinero, que se reembolsará en el plazo máximo de cinco años. En este caso, las partes son libres para pactar la forma de reconocer la titularidad de esos fondos que se integrarán en la sociedad resultante de la transformación, y para el caso de falta de acuerdo se propone como solución su acreditación como un crédito retribuido y reembolsable en un plazo máximo de cinco años.

En el caso de transformación de cooperativa de crédito, si su FRO va a integrarse en el capital social de la entidad resultante de la transformación, las acciones correspondientes deberían acreditarse a quien conforme a la legislación cooperativa sería el destinatario de esos fondos. Ante el silencio de la Ley de Cooperativas de Crédito ${ }^{22}$ procedería aplicar el art. 75 de la LC 27/99 según el cual, debería acreditarse a la sociedad cooperativa o entidad federativa ${ }^{53}$ que figura expresamente recogida en los Estatutos o que se designe por acuerdo de la Asam-

52 La LCC guarda silencio pero su Reglamento, aprobado por RD 84/93 en su art. 34.2 señala que en los supuestos de liquidación de una cooperativa de crédito, el activo sobrante y el remanente del fondo a que se refiere el artículo anterior, se podrán a disposición del Instituto Nacional de Fomento de la Economía Social (INFES), que deberá destinarlo, de modo exclusivo, a la promoción del cooperativismo. Esta institución desapareció y sus funciones fueron asumidas por la actual Dirección General de la Economía Social, del Trabajo Autónomo y de la Responsabilidad Social de las Empresas. No obstante, entendemos que esta norma no es aplicable por contradecir otra de rango superior como es la LC 27/1999.

53 Son entidades federativas potencialmente destinatarias de estos fondos, la Federación de Cajas Rurales de la Comunidad Valenciana, la Asociación Nacional de Cajas Rurales, la Confederación de Cooperativas Vascas, etc. 
blea general; y de no producirse designación correspondería a la Unión Nacional de Cooperativas de Crédito (UNACC), entidad que agrupa a todas las cooperativas de crédito y que entre sus objetivos tiene, conforme a sus estatutos, fomentar la promoción del cooperativismo de crédito (art. 3).

Esta solución permite compaginar los intereses de solvencia de la nueva entidad y la garantía del destino de los fondos irrepartibles a la promoción del cooperativismo. La entidad destinataria de dichas acciones representativas del FRO podrá destinar los beneficios que estas generen a la promoción del cooperativismo, así como, en su caso, el importe obtenido por la enajenación de aquellas. 